\title{
Three-Dimensional Intersection Method for Monitoring and Analysis of Horizontal and Vertical Movements of Buildings
}

\author{
Dr. Khalid L. A. El-Ashmawy \\ Department of Civil Engineering \\ College of Engineering and Islamic Architecture \\ Umm Al-Qura University \\ Makkah \\ Saudi Arabia
}

\begin{abstract}
Deformation monitoring of the engineering structures such as buildings provides information about the health of the structures and their safety aspects as well as the safety of the public.

This paper describes the development of a method for the monitoring and analysis of vertical and horizontal movements of structures. The proposed method is developed to add a new solution to traditional methods of the three-dimensional intersection for getting the spatial coordinates of points. A software was developed to provide a simultaneous solution to all observations and data in one step using-least squares solution to improve the expected accuracy and to generate the necessary data for statistical analysis.

The proposed method was used for monitoring and analyzing the movements of a high-rise buildings in Cairo, Egypt. A traverse of four points and well distributed twenty three monitoring points were used. All measurements were taken using total station.

The observations were carried out at four epochs of two-month interval. The developed software was used for getting the adjusted ground coordinates of the monitoring points, observations and generating the necessary statistical data.

The results of the first epoch were used as reference values such that the subsequent epochs values were compared with them to compute the horizontal and vertical movements of the monitoring points for each epoch. Furthermore, values of horizontal and vertical movements were compared with their corresponding computed $95 \%$ confidence intervals to determine the significance of the existing displacement. The results show the horizontal and vertical stability of the building during the monitoring period. The case study shows the efficiency of the proposed method for the monitoring of the deformation of the building structures. It is strongly recommended that engineering structures especially high-rise buildings should be monitored on a regular basis to check their stability and thereby increasing their safety.
\end{abstract}

Key Words: Deformation Monitoring, Horizontal and Vertical Movements, Three-Dimensional Intersection, Accuracy Analysis.

\section{INTRODUCTION}

By the influence of various internal, external, as well as other causal factors, to soil and structures, vertical and horizontal movements of objects occur. Movement can be defined as a change of the position of a point in space, which is divided into a horizontal and a vertical component. The consequence of deformation is the stress of the structure, unpredicted by calculations, which causes cracks and/or damages, and in extreme cases even collapse of objects or some structural parts.

The purpose of a deformation monitoring or survey is to determine whether or not the movement is taking place and subsequently whether the structure is stable and safe. Movement can be further analyzed to see if it is due to seasonal factors, daily variances, etc and then, more importantly, use the information to determine the future movement of the structure [1]. It is important to measure this movement for the purpose of safety assessment and as well as preventing any disaster in the future [2].

A monitoring system can insure the structural safety of a building by providing continues deformation data over extended periods of time. This allows suitable and cost effective maintenance to be applied [3].

Recently, it is possible to use a number of different procedures of deformation monitoring, such as topographic networks for three-dimensional (3D) control using total stations or geometric leveling. These may be combined with more complex procedures such as portable digital photogrammetric stations (DPS) or a terrestrial laser scanner (TLS) system [4]. However, in general, these non-contact technologies require the use of specialized instrument that is not readily available to most surveyors. This instrument is expensive to buy or rent and additional costs can be incurred because of the need to train or hire personnel 
capable of managing and modeling its data. Moreover, the amount of data acquired by a TLS system makes it difficult to produce 3D models. There are many software systems available to be used for this task, but these consume computing and time resources and again special instrument must be bought or hired. These techniques, therefore, have significant limitations, confining their use almost exclusively to some applications where the available budgets and resources are both significantly higher.

Furthermore, even excluding the issues of cost and complexity, these techniques have other problems, mainly concerning the accuracy of the measurements they produce [5]. Changes in environmental conditions such as temperature and humidity [6], different colors and materials reflectivities, the effects of angle of incidence [7], and problems due to close-range imaging may produce dimensional errors in the 3D model [8]. Depending on these conditions, significant errors in the measurement of deformations can occur, extending sometimes to an order of magnitude of more than $1 \mathrm{~cm}$, compared with direct measurements [9].

To overcome some of the above mentioned problems, a cost effective methodology for monitoring horizontal and vertical movements of buildings will be presented in this paper. The aims of the present research are (1) developing a proposed method depending on a mathematical model for computing the spatial coordinates from the measurements of theodolite or total station, (2) developing a software for the proposed method, and (3) employing the proposed method for the deformation monitoring of a case study building.

\section{METHODOLOGY}

\subsection{Derivation of the Mathematical Model}

Three-dimensional intersection is the determination of the horizontal and vertical positions of a point by observations from two or more points of known position. A wide variety of angle, azimuth direction and distance measuring instruments may be used. These include the surveying transits, theodolites, and total stations.

Figure 1 illustrates the geometry of the three-dimensional intersection technique. A three-dimensional rectangular coordinates system is needed to calculate the spatial coordinates of any target points. There are two known coordinates points ( $X_{A}, Y_{A}, Z_{A}$ ) and $\left(X_{B}, Y_{B}, Z_{B}\right.$ ). From these two known points (A and B), we can determine the coordinates of unknown point $\mathrm{C}$ $\left(X_{C}, Y_{C}, Z_{C}\right)$.

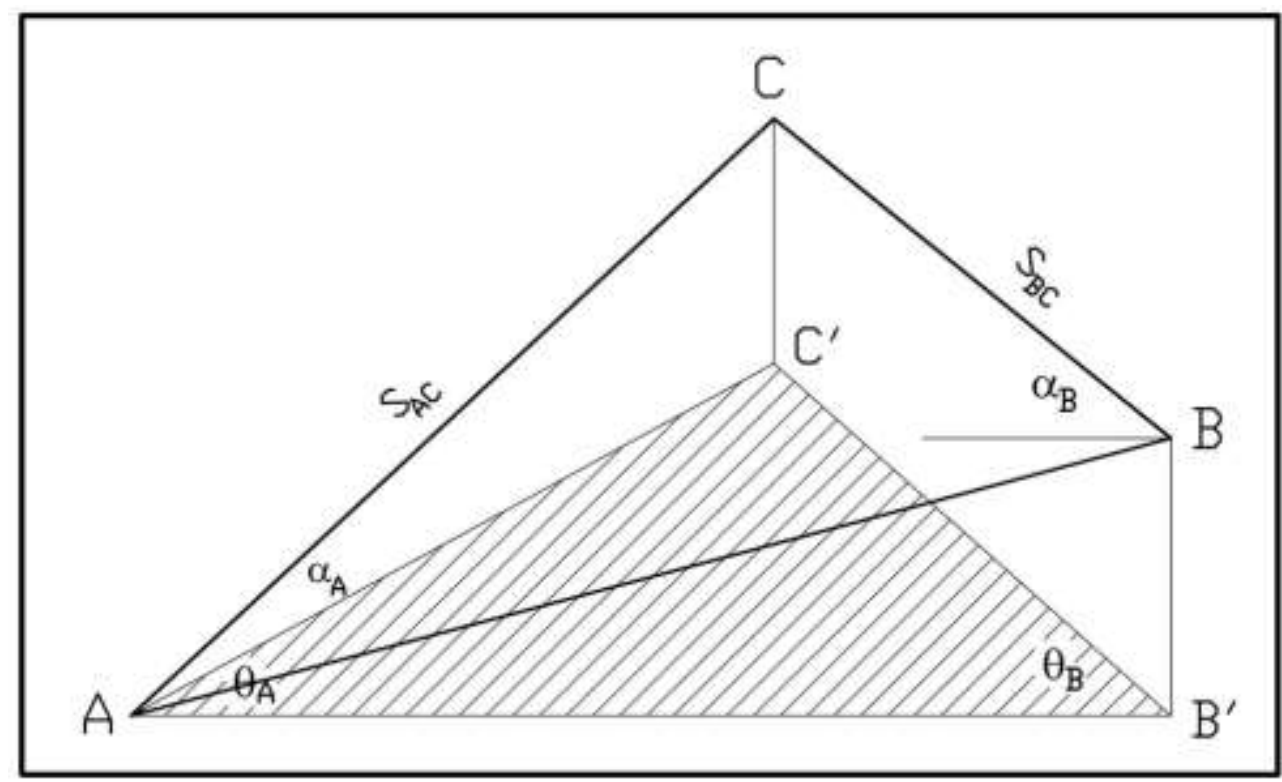

Figure 1. Three-Dimensional Intersection

Two cases will arise depending on the observations and the used instruments for the intersection technique:

- Three-dimensional intersection using angular data: In this case, the horizontal angles $\theta_{A}, \theta_{B}$ and the vertical angles $\alpha_{A}, \alpha_{B}$ are the angular observations from two known stations $\mathrm{A}$ and $\mathrm{B}$ to the unknown station $\mathrm{C}$. Since, the number of observations (four in this case) is greater than the number of unknowns (three spatial coordinates of point $\mathrm{C}$ ), Least 
Squares Technique (LST) should be used to compute the spatial coordinates of point B and its accuracy. In this case, the redundancy number equals one and increases by increasing the occupied points.

- Three-dimensional intersection using angular and distances data: The observations include the horizontal and vertical angles and the slope distances $S_{A C}$ and $S_{B C}$ form stations A and B to station C. The number of observations becomes six which is greater than the number of unknowns. Least Squares Technique should be applied to obtain the spatial coordinates of point $\mathrm{C}$. In this case, the redundancy number will be three and increase by increasing the occupied points.

The developed mathematical model utilizes the geometric relation between the observations and the unknowns to establish six equations for each measured object space coordinates of a point, and provides a unique solution for the system of observation equations by the least squares method. The mathematical model can be written as:

$$
\begin{aligned}
& S_{A C}=\sqrt{\left(X_{C}-X_{A}\right)^{2}+\left(Y_{C}-Y_{A}\right)^{2}+\left(Z_{C}-Z_{A}\right)^{2}} \\
& S_{B C}=\sqrt{\left(X_{C}-X_{B}\right)^{2}+\left(Y_{C}-Y_{B}\right)^{2}+\left(Z_{C}-Z_{B}\right)^{2}} \\
& \theta_{A}=\cos ^{-1}\left(\frac{\left(X_{C}-X_{A}\right)^{2}+\left(Y_{C}-Y_{A}\right)^{2}+A B^{2}-\left(X_{C}-X_{B}\right)^{2}-\left(Y_{C}-Y_{B}\right)^{2}}{2 A B \sqrt{\left(X_{C}-X_{A}\right)^{2}+\left(Y_{C}-Y_{A}\right)^{2}}}\right) \\
& \theta_{B}=\cos ^{-1}\left(\frac{\left(X_{C}-X_{B}\right)^{2}+\left(Y_{C}-Y_{B}\right)^{2}+A B^{2}-\left(X_{C}-X_{A}\right)^{2}-\left(Y_{C}-Y_{A}\right)^{2}}{2 A B \sqrt{\left(X_{C}-X_{B}\right)^{2}+\left(Y_{C}-Y_{B}\right)^{2}}}\right) \\
& \alpha_{A}=\tan ^{-1}\left(\frac{\left(Z_{C}-Z_{A}\right)}{\sqrt{\left(X_{C}-X_{A}\right)^{2}+\left(Y_{C}-Y_{A}\right)^{2}}}\right) \\
& \alpha_{B}=\tan ^{-1}\left(\frac{\left(Z_{C}-Z_{B}\right)}{\sqrt{\left(X_{C}-X_{B}\right)^{2}+\left(Y_{C}-Y_{B}\right)^{2}}}\right)
\end{aligned}
$$

These equations are nonlinear function of both parameters and observations. The linearized form of these equations can be given as:

$$
V+B . \Delta=\varepsilon
$$

where

$\Delta \quad$ is the correction vector to the current values set for the unknowns (the object space coordinates of point C) in the iterative solution;

$B \quad$ is the matrix of the partial derivatives of the observation equations with respect to the unknowns;

$V \quad$ is the residual vector, i.e., the correction vector to the measured observations; and

$\varepsilon \quad$ is the discrepancy vector.

The parametric least squares solution of equation (7) can be given as [10]:

$$
\begin{aligned}
& \Delta=N^{-1} \cdot C \\
& N=\bar{B}^{t} \cdot W^{-1} \cdot \bar{B} \\
& C=\bar{B}^{t} \cdot W^{-1} \cdot \bar{\varepsilon}
\end{aligned}
$$


Where $W$ is the weight matrix of observations.

\subsection{Developing 3D Intersection software}

The current research includes the development of software for the applications of three dimensional intersection technique. The software is written in Visual C++ [11] and utilizing efficient techniques of Data Structuring, Random File Access and Dynamic Memory Allocations for automatic processing and representation of the data and results [12]. The software has been designed to make use of efficient user interfaces (window-driven) for facilitating its execution to the user.

3D-Intersection software reads the input data and observations in the form of measured horizontal and vertical angles; or measured horizontal, vertical angles and slope distances; and the X, Y, Z spatial coordinates of the known points, and computes its output by using least squares technique.

The software automatically generates its output in numerical and graphical forms. The numerical output, in the form of ASCII file format, includes variance of unit weight, adjusted spatial coordinates of unknown stations and their standard deviations (optional), residuals of observations, corrected observations and their cofactor matrix (optional), and dimensions of the error ellipses (optional). The software has also the capability of automatic generation of its output in data structural format namely point-oriented (which includes for each point elements such as point number, adjusted ground coordinates, standard deviations, etc.). This enables the generated results to be systematically documented for proper storage in data bank and retrieval.

The graphical output, in the form of DXF file format, consists of, if any, plots for the location of the points with error ellipses.

\subsection{Deformation Analysis}

After getting the adjusted spatial coordinates of the object points for each epoch, the results of the first epoch are used as reference values such that the subsequent epochs values are compared with them. In this case, the values of the displacements of each object point can be obtained as:

$$
\left.\begin{array}{l}
d X=X_{\text {Frist epoch }}-X_{\text {Current } \text { epoch }} \\
d Y=Y_{\text {Frist epoch }}-Y_{\text {Current } \text { epoch }} \\
D=\sqrt{d X^{2}+d Y^{2}} \\
\eta=\tan ^{-1} \frac{d X}{d Y} \\
d Z=Z_{\text {Frist epoch }}-Z_{\text {Current epoch }}
\end{array}\right\}
$$

where,

$X, Y, Z=$ the adjusted spatial coordinates of the object point,

$d X, d Y, d Z=$ displacements in $\mathrm{X}-, \mathrm{Y}$ - and Z-directions respectively,

$D=$ the magnitude of horizontal movement, and

$\eta=$ the direction of the horizontal movement.

The classical method for checking stability of monitoring points involves comparing the differences in spatial coordinates obtained in the initial observations (first epoch) and existing (current epoch) as shown in equation (11).

Modern deformation modeling methods involve the application of statistical tests on each epoch of measurements to determine whether point movements are significant. Determination of the significant of point movements is based on comparing the computed movements with their corresponding $95 \%$ confidence intervals [13].

If the movement magnitudes of a point $\mathrm{j}$ are classified $D_{j}$ and $d Z_{j}$ (equation 11) and the maximum dimension of combined $95 \%$ confidence ellipse for point $\mathrm{j}$ is designated $E D_{j}$ and $\mathrm{E} Z_{j}$, then, if $D_{J}\left\langle E D_{J}\right.$ it can be concluded that no horizontal movement has occurred in point $\mathrm{j}$ and the observed difference is due to errors in measurement. Furthermore, if $D_{J}>E D_{J}$ then it can be concluded that point horizontal movement has occurred [14]. Similarly, conclusion for the movements in Z-directions can be obtained.

For example, $E D_{J}$ can be computed as: 
International Journal of Advances in Scientific Research and Engineering (ijasre), Vol 5 (10), October-2019

$$
E D_{J}=1.96 \sqrt{\left(m_{\Delta J}^{k+1}\right)_{X}^{2}+\left(m_{\Delta J}^{k}\right)_{X}^{2}}
$$

in which,

$\left(m_{\Delta J}^{k+1}\right)_{X}$ is the standard error for the horizontal movement of point $\mathrm{J}$ in the current epoch, and

$\left(m_{\Delta J}^{k}\right)_{X}$ is the standard error in the horizontal movement of point $\mathrm{J}$ in the previous epoch.

\section{CASE STUDY}

The monitored building was a high-rise big building in Cairo, Egypt. The building is a six-story one of 55.0m in length, $25.0 \mathrm{~m}$ in breadth and $18 \mathrm{~m}$ in height. The building has front, back and side facades as shown in Figure 2.

\subsection{Choice of points}

To effectuate the deformation monitoring of the case study building, in the first step the recognition of the field has been made. In this step, four local reference points were chosen as shown in Figure 2. These points were positioned around the building at a safe distance in order to consider that they were not affected by the movements of the building.

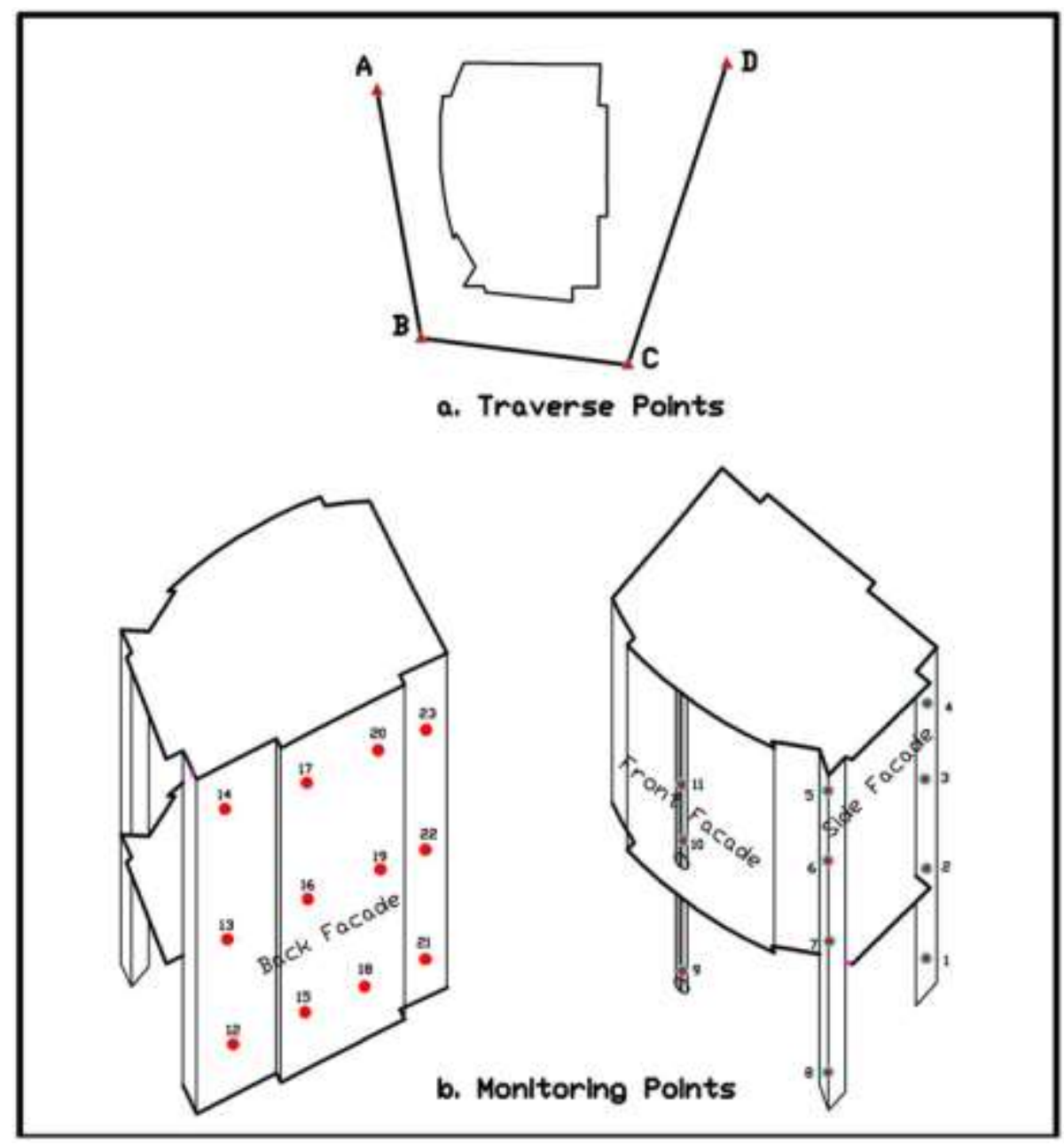

Figure 2. Location of traverse and monitoring points of the case study

In the deformation monitoring project of the case study building, 23 object points were positioned on the three facades of the building in order to determinate the stability of the structure. Those object points were positioned on the concrete columns and on the external walls as shown in Figure 2. The object points are well distributed over the whole facades. The marked monitoring points were made permanent by fixing sheet prisms with diameter $(1 \mathrm{~cm})$.

\subsection{Measurements}


The suggested monitoring system of the building consists of small open-traverse around the building (Figure 2). The main objective of the four stations open-traverse is to provide a number of stations whose positions, are accurately established.

The local ground coordinates of station $\mathrm{A}\left(X_{A}, Y_{A}, Z_{A}\right)$, and the azimuth of line $\mathrm{AB}$ were assumed. The observations for the traverse consisted of horizontal and vertical angles and three distances using Topcon GTS 255 total station. This combined system of measuring angles and distances represents the strongest network for creating horizontal control. The angles were measured on four arcs and the distances were measured four times. Then all data and observations of the traverse were entered to LandSurMap software [15] for getting the adjusted coordinates of the traverse and statistical data using an iterative least squares adjustment technique.

The levels of the traverse stations were determined using geometric precise leveling starting from station A. The measurements of precise leveling were taken using Leica NA2 level and Leica (10 mm) GPM3 parallel plate micrometer attachment and a GPLE3 invar staff with $10 \mathrm{~mm}$ graduations [16].

The observations and the adjustment of the traverse were done only one time at the first epoch of monitoring observations.

Having determined the local ground coordinate of the traverse stations, the total station was set-up on each traverse stations and the slope distances, vertical angles and horizontal angles to the available monitoring points were measured.

The observations for the case study were carried out at four epochs of two-months interval.

\subsection{Data processing and results}

Processing the data was performed using the developed 3D-Intersection software. Measurements and geodetic data e.g. slope distances, horizontal and vertical angles, and ground coordinates of the traverse stations and their standard deviations for each epoch of observations were entered to the software by editing a suitable data file. Three iterations were required to get the final results of the least squares technique adjustment. The results were received in the form of, as mentioned before, variance of unit weight, adjusted ground coordinates of monitoring points and their standard deviations, residuals of observations, and corrected observations and their cofactor matrix.

The maximum variances of unit weight of all observations epochs was $2.46 \mathrm{~mm} 2$ and the corresponding standard error was $1.57 \mathrm{~mm}$ which show the high precision and accuracy of the adjusted observations.

The standard deviations of monitoring points coordinates for the first observations epoch were varied from $0.8 \mathrm{~mm}$ to 1.3 $\mathrm{mm}$ in the horizontal components, and from $1.3 \mathrm{~mm}$ to $2.2 \mathrm{~mm}$ in vertical component. While in the second epoch, the corresponding values are varied from $1.2 \mathrm{~mm}$ to $2.5 \mathrm{~mm}$ in horizontal components and from $1.6 \mathrm{~mm}$ to $2.7 \mathrm{~mm}$ in vertical component. For third observation epoch, the standard deviations points coordinates were varied from $1.5 \mathrm{~mm}$ to $2.7 \mathrm{~mm}$ in the horizontal components, and from $1.8 \mathrm{~mm}$ to $2.8 \mathrm{~mm}$ in vertical component. Finally, the standard deviations of monitoring points coordinates for the fourth observations epoch were varied from $1.4 \mathrm{~mm}$ to $2.9 \mathrm{~mm}$ in the horizontal components, and from $2.0 \mathrm{~mm}$ to $2.8 \mathrm{~mm}$ in vertical component. Practically, the overall data analysis has shown that the qualities of the observations and results are good.

The results of the first epoch were used as reference values such that the subsequent epochs results were compared with them. The differences in ground coordinates between the first and the subsequent epochs adjusted coordinates, and the magnitude and direction of the horizontal movement were respectively computed. Table 1 shows the ground coordinates differences and magnitude and direction of the horizontal movement for the observation epochs.

The differences in horizontal and vertical movements between the first and the subsequent epochs respective confidence intervals at $95 \%$ confidence level were determined using equations (12) and tabulated in Table 2. The horizontal and vertical movements magnitudes of the monitoring points/building at each epoch were computed and compared with their corresponding confidence intervals at $95 \%$ confidence level to determine if the computed movements were actual movements of the structure (significant) or they were due to measurement errors.

Table 1. The magnitude and direction of the horizontal movement at the observation epochs.

\begin{tabular}{|c|c|c|c|c|c|c|c|c|c|c|c|c|c|c|c|c|}
\hline \multirow[b]{2}{*}{ Point } & \multicolumn{4}{|c|}{ Epoch (1) } & \multicolumn{4}{|c|}{ Epoch (2) } & \multicolumn{4}{|c|}{ Epoch (3) } & \multicolumn{4}{|c|}{ Epoch (4) } \\
\hline & $\begin{array}{c}\mathrm{dX} \\
\mathrm{mm}\end{array}$ & $\begin{array}{l}\mathrm{dY} \\
\mathrm{mm}\end{array}$ & $\begin{array}{c}\mathrm{D} \\
\mathrm{mm}\end{array}$ & $\eta^{0}$ & $\begin{array}{l}\mathrm{dX} \\
\mathrm{mm}\end{array}$ & $\begin{array}{l}\mathrm{dY} \\
\mathrm{mm}\end{array}$ & $\begin{array}{c}\mathrm{D} \\
\mathrm{mm}\end{array}$ & $\eta^{0}$ & $\begin{array}{l}\mathrm{dX} \\
\mathrm{mm}\end{array}$ & $\begin{array}{l}\mathrm{dY} \\
\mathrm{mm}\end{array}$ & $\begin{array}{c}\mathrm{D} \\
\mathrm{mm}\end{array}$ & $\eta^{0}$ & $\begin{array}{l}\mathrm{dX} \\
\mathrm{mm}\end{array}$ & $\begin{array}{l}\mathrm{dY} \\
\mathrm{mm}\end{array}$ & $\begin{array}{c}\mathrm{D} \\
\mathrm{mm}\end{array}$ & \\
\hline P1 & 0.0 & 0.0 & 0.0 & 0.0 & -3.8 & 3.2 & 5.0 & 310.1391 & -1.6 & 3.8 & 4.1 & 337.1838 & 5.2 & 4.8 & 7.1 & 47.254 \\
\hline
\end{tabular}




\begin{tabular}{|c|c|c|c|c|c|c|c|c|c|c|c|c|c|c|c|c|}
\hline P2 & 0.0 & & & & -4.6 & 2.6 & 5.3 & & -4.8 & -1.8 & 5.1 & & -1.8 & -3.6 & 4.0 & \\
\hline P3 & 0.0 & & & & & 30 & 48 & & 4.6 & & & & & & & \\
\hline P4 & & & & & & 2.4 & & & & & & & & & & \\
\hline P5 & & & & & & 8 & & & & & & & & & & \\
\hline P6 & .0 & & & & 0.2 & -2.2 & 2.2 & & -1.4 & 5 & & & & & & 49.9748 \\
\hline P7 & & & & & 3.4 & -3.8 & 5.1 & & 4.4 & -1. & 4. & & .2 & & & 5.2594 \\
\hline P8 & & & & & -0.4 & 1.6 & 1. & & -4.4 & -3. & 5. & & 3.1 & & & \\
\hline P9 & & & & & 0. & & & & & & & & & & & \\
\hline 10 & & & & & 3. & & D. & & & 3. & & & & & & \\
\hline 11 & 0.0 & & & & & 2.0 & 2. & & 4. & 1. & & & & & & 422 \\
\hline P12 & 0.0 & & & & 4.0 & -1.4 & 4. & & -3.4 & -0. & & & & & . & 60.5958 \\
\hline P13 & & & & & & & & & 4.8 & -2 & & & & & & \\
\hline P14 & 0 & & & & 2.4 & 1.8 & 3. & & -1.6 & -1.2 & 2.1 & & -4.6 & 3.2 & & \\
\hline P15 & 0.0 & & & & -2 & 4.0 & 4.9 & & 0.6 & 4.8 & & & 4. & 1. & 4. & \\
\hline 16 & 0 & & & & 2.2 & 3.8 & 4.4 & & -0.6 & 1 & & & 4. & -4 & 6. & \\
\hline 217 & 0.0 & & & & & 3. & 3.4 & & -4.6 & T & & & 2. & -4. & 5. & 52.468 \\
\hline P18 & 0.0 & & & & & 1.8 & 1. & & 2.8 & 3. & 4. & 22 & 1 & 3.8 & & 22.8162 \\
\hline P19 & 0.0 & & & & -2.4 & & 2 & & 1 & -3. & & & & & & 270.000 \\
\hline P20 & 0.0 & & & & 2.2 & -2.4 & 3.3 & & -0 & 4. & & & -1 & & & 45 \\
\hline 21 & 0.0 & & 0. & & 0.0 & -1.2 & 1.2 & & -3. & -4.6 & & & 2.2 & -1.0 & 2. & 14.494 \\
\hline & 0.0 & & & & 3.8 & 0.6 & 3.8 & & -3. & -1.2 & 3. & & 2. & -0.4 & & \\
\hline 125 & 0.0 & & & & -0.2 & 0.8 & 0.8 & 345.9745 & -2.6 & -1.6 & 3.1 & 238.3478 & 1.6 & 1.6 & 2.3 & 44.9655 \\
\hline
\end{tabular}

Table 2. Analysis of the horizontal and vertical movements for the monitoring points

\begin{tabular}{|c|c|c|c|c|c|c|c|c|c|c|c|c|c|c|c|c|c|c|}
\hline \multirow[b]{2}{*}{ Point } & \multicolumn{6}{|c|}{ Epoch (2) } & \multicolumn{6}{|c|}{ Epoch (3) } & \multicolumn{6}{|c|}{ Epoch (4) } \\
\hline & $\begin{array}{c}\mathrm{D} \\
\mathrm{mm}\end{array}$ & $\begin{array}{l}\text { ED } \\
\mathrm{mm}\end{array}$ & 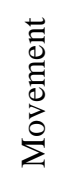 & $\begin{array}{c}\mathrm{dZ} \\
\mathrm{mm}\end{array}$ & $\begin{array}{l}\text { EZ } \\
\mathrm{mm}\end{array}$ & $\begin{array}{l}\overrightarrow{0} \\
\overrightarrow{0} \\
0 \\
\text { D } \\
\Sigma\end{array}$ & $\begin{array}{c}\mathrm{D} \\
\mathrm{mm}\end{array}$ & $\begin{array}{l}\text { ED } \\
\mathrm{mm}\end{array}$ & 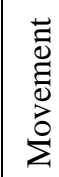 & $\begin{array}{c}\mathrm{dZ} \\
\mathrm{mm}\end{array}$ & $\begin{array}{c}\mathrm{EZ} \\
\mathrm{mm}\end{array}$ & 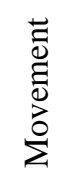 & $\begin{array}{c}\mathrm{D} \\
\mathrm{mm}\end{array}$ & $\begin{array}{l}\mathrm{ED} \\
\mathrm{mm}\end{array}$ & 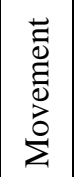 & $\begin{array}{c}\mathrm{dZ} \\
\mathrm{mm}\end{array}$ & $\begin{array}{l}\mathrm{EZ} \\
\mathrm{mm}\end{array}$ & 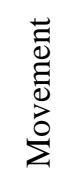 \\
\hline P1 & 5.0 & 6.0 & No & -5.4 & & No & 4.1 & 6.4 & $\mathrm{No}$ & -5.8 & 6.9 & No & 7.1 & 8.3 & No & 0.4 & 3.4 & $\mathrm{No}$ \\
\hline $\mathbf{P 2}$ & 5.3 & 7.2 & No & -6.2 & & No & 5.1 & 7.1 & No & 2.8 & 5.5 & No & 4.0 & 6.4 & No & & 4.5 & No \\
\hline P3 & 4.8 & 6.4 & No & -3.8 & 55 & No & 6.9 & 7.7 & No & 2.8 & 6.5 & No & 4.9 & 6.7 & No & 2. & 5.4 & No \\
\hline P4 & 3.5 & 5.6 & $\mathrm{~N}$ & -0 . & & & & 5.5 & $\mathrm{No}$ & -4.4 & 4.6 & No & 2.6 & 6.5 & No & & 4.7 & No \\
\hline P5 & 2.3 & 5.6 & $\mathrm{~N}$ & -3.1 & 4 & $\mathrm{~N}$ & 3 & 5.8 & No & -4.6 & 6.5 & No & 4.4 & 5.6 & No & -0 & 4.8 & No \\
\hline P6 & 2.2 & 5.7 & $\mathrm{~N}$ & -4.2 & 6. & $\mathrm{~N}$ & & 6.6 & No & -5.6 & 5.9 & No & 4.0 & 5.8 & No & & 5. & No \\
\hline P7 & 5.1 & 6.1 & No & -2.6 & & $\mathrm{~N}$ & & 7.2 & $\mathrm{No}$ & -1.8 & 4.5 & No & 2.2 & 5.2 & No & & 5.6 & No \\
\hline P8 & 1.6 & 4.7 & No & 2.0 & 4.5 & No & 5.7 & 7.5 & No & 3.4 & 5.4 & No & 5.0 & 5.9 & No & & & No \\
\hline P9 & 3.8 & 6.5 & No & 4.4 & 4.6 & No & 4.8 & 7.1 & No & 1.0 & 4.8 & No & 5.7 & 6.7 & No & & & No \\
\hline P10 & & 7.1 & No & -2. & & No & & 8.1 & $\mathrm{No}$ & -3.6 & 5. & No & 5.3 & 5.6 & No & & & No \\
\hline P11 & 2.7 & 6.5 & No & 0. & & & & 6.4 & $\mathrm{~N}$ & -4.0 & 5.6 & No & 4.4 & 7.0 & No & & & No \\
\hline P12 & 4.2 & 6.6 & No & 3. & & $\mathrm{~N}$ & 3. & 6.6 & No & -3.4 & 5.6 & No & 3.7 & 5.0 & No & & 4.8 & No \\
\hline P13 & 2. & 5.1 & No & -2 . & & & & 6.6 & No & 5.1 & 5.5 & No & 2.9 & 6.4 & \begin{tabular}{|l|} 
No \\
\end{tabular} & & 5.1 & No \\
\hline P14 & 3.0 & 5.8 & No & 0.2 & 4 & No & 2.1 & 5.7 & $\mathrm{No}$ & 1.6 & 4.6 & No & 5.6 & 6.9 & No & & 4.9 & No \\
\hline P15 & 4.9 & 5.6 & No & -0.8 & 4.2 & No & 4.8 & 6.4 & No & 3.4 & 4.6 & No & 4.7 & 5.7 & No & 1.2 & 4.8 & No \\
\hline P16 & 4.4 & 7.8 & No & 5.1 & & No & 1.9 & 5.0 & $\mathrm{No}$ & 4.6 & 4.6 & No & 6.4 & 7.0 & \begin{tabular}{|l} 
No \\
\end{tabular} & & 6. & No \\
\hline P17 & 3.4 & 6.3 & No & 4. & & $\bar{N}$ & & 6.7 & $\mathrm{No}$ & 5.4 & 6. & No & 5.2 & 7.1 & No & & & No \\
\hline P18 & 1.8 & 5.4 & No & 2. & & $\mathrm{~N}$ & & 7. & $\mathrm{No}$ & -3.2 & 5. & No & 4.1 & 6.7 & No & & & No \\
\hline P19 & & & No & 2. & & & & 4.9 & $\mathrm{No}$ & 0.2 & 4. & No & 1.2 & 5.6 & No & & 5.4 & No \\
\hline P20 & 3.3 & 6.5 & No & -4.8 & & & 4.8 & 5.8 & $\mathrm{No}$ & 2.4 & 5.4 & No & 4.9 & 7.2 & No & 5.1 & 5.4 & No \\
\hline P21 & 1.2 & 4.8 & No & -2.8 & & & 5.8 & 6.4 & No & -3.0 & 5.5 & No & 2.4 & 6.5 & No & -4.4 & 5.1 & No \\
\hline P22 & 3.8 & 5.5 & No & 5.4 & & No & 3.2 & 6.5 & No & -4.2 & 6.9 & No & 2.8 & 7.1 & No & 5.2 & 6.4 & No \\
\hline P23 & 0.8 & 4.9 & No & -1.8 & 4.5 & No & 3.1 & 6.6 & $\mathrm{No}$ & -4.6 & 5.4 & No & 2.3 & 6.4 & No & -6.2 & 6.5 & $\mathrm{No}$ \\
\hline
\end{tabular}

It can be concluded from Tables 1 and 2 that the evaluated movements magnitudes were all less than their corresponding confidence intervals showing that the building did not undergo any horizontal or vertical movement during the period of monitoring.

\section{CONCLUSIONS AND RECOMMENDATIONS}


The proposed method is accurate and efficient for the determination of the horizontal and vertical movements of the structures.

The proposed method can be used for the practical determination of the inclination of buildings, by measuring the horizontal displacement of the top of the building relative to the bottom, which is one of the important means to provide scientific basis for the safe and effective means of building emergency. The building safety can grasp only by building subsidence observation and using the specific computations, which will provide a scientific basis for experts to make scientific decision.

The results of the four epochs, for the case study, were compared after comprehensive analyses of the results obtained at various stages and the final analysis of the datasets. From the analysis, the building is stable both vertically and horizontally. Therefore the building is safe and in a good habitable condition.

Structural collapses, damages and loss of lives could be averted if regular deformation monitoring is carried out on such buildings or structures at specific intervals. For this reason, it is strongly recommended that engineering structures especially high rise buildings should be monitored at regular basis to check their stability and thereby increasing their safety.

\section{REFERENCES}

1. Aghedo, H. O. "Deformation Monitoring of Ikpoba River Bridge in Benin City, Edo State, Using GPS", Unpublished MSc Thesis of the Department of Surveying and Geoinformatics, Nnamdi Azikiwe University,Awka., 2016.

2. Aziz, W. A., Othman, Z. and Najib, H. "Monitoring High-Rise Building Deformation using Global Positioning System", Asian GPS Conference., 2001.

3. Abdullahi, I. M. and Yelwa, N. A. "Structural Deformation Monitoring Surveys of New Administrative Building of Federal School of Surveying, Oyo-Nigeria”, International Journal of Science and Technology, Vol. 6, No.1., 2016.

4. Fregonese, L. et al. "Surveying and Monitoring for Vulnerability Assessment of an Ancient Building”, Sensors, pp.97479773., 2013.

5. Alkan, R.M., and Karsidag, G. "Analysis of the accuracy of terrestrial laser scanning measurements", In FIG Working Week 2012. Rome, Italy: International Federation of Surveyors (FIG), p. 16., 2012.

6. Durán-Dominguez, G., Felicisimo, A., and Polo, M.-E. "3D study of cultural heritage for conservation. Reliability of the portable 3D laser scanners", In International Congress on Science and Technology for the Conservation of Cultural Heritage. Seville, Spain, 2014.

7. Berenyi, A., Lovas, T., and Arpad Barsi "Terrestrial laser scanning in engineering survey: analysis and application examples", In ASPRS 2010 Annual Conference. San Diego, California: American Society for Photogrammetry and Remote Sensing, p. 8., 2010.

8. Cosarca, C., Jocea, A., and Savu, A. “Analysis of error sources in Terrestrial Laser Scanning”, RevCAD - Journal of Geodesy and Cadastre, 9, pp.115-124., 2009.

9. Dumalski, A. "Evaluation of possible application of terrestrial laser scanner - scanstation in vertical displacement measurements", Technical Sciences, 14(1), pp.33-43, 2011.

10. Mikhail, E. M. “Observations and Least squares”, Thomas Y. Crowel Company, Inc., 1983.

11. Gregory, K., “Special Edition Using Visual C++ 6”, Que, USA., 1998.

12. Malik, D.S. “Data Structures Using C++”, Second Edittion. Cengage Learing, Inc., USA., 2010.

13. Bird, B. “Analysis of Survey Point Displacements Using Total Station Measurements”, Published BSc. Technical Report of the Department of Geomatics Engineering, British Columbia Institute of Technology, 2009.

14. Okiemute, E. S., Ono Matthew, N., and Fatai, O. O. "Monitoring and Analysis of Vertical Deformation of Palm House Benin City Using Digital Level”, International Journal of Advances in Scientific Research and Engineering (ijasre), 4(9), pp. 6-16., 2018

15. El-Ashmawy, K. "Development of a Land Survey System with CAD/GIS Interfacing Capabilities", Alexandria Engineering Journal, Faculty of Engineering, Alexandria University, Egypt, Vol. 41, No. 6, pp 1041-1050, 2002. 
International Journal of Advances in Scientific Research and Engineering (ijasre), Vol 5 (10), October-2019

16. Leica. [online \}, [cited 12 May 2019]. Available from Internet: http://ptd.leica-geosystems.com/en/index.htm, (2019) 